Fl uor ogeni $c$ al dehydes bear ing aryl et hynyl groups: turn- on al dol react i on sensor $s$ for eval uat i on of or ganocat al ysi s i $n$ DNSO

\begin{tabular}{|c|c|}
\hline 著者 & $\begin{array}{l}\text { Nase Nobuyuki, Ando Tai shi, Shi bagaki Fum ya, } \\
\text { Sugi t a At sushi, Nar um Tet suo, Toda M t suo, } \\
\text { Wat anabe Naohar u, Tanaka Fuj i e }\end{array}$ \\
\hline $\begin{array}{l}\text { journal or } \\
\text { publ i cat } i \text { on } t i t l e\end{array}$ & Tet rahedr on Let ters \\
\hline vol une & 55 \\
\hline nunber & 11 \\
\hline page $r$ ange & 1946- 1948 \\
\hline year & $2014-03-12$ \\
\hline 出版者 & El sevi er \\
\hline 権利 & $\begin{array}{l}\text { Copyr i ght ( C) } 2014 \text { El sevi er Ltd. Al I ri ght s } \\
\text { reser ved. }\end{array}$ \\
\hline 注記 & 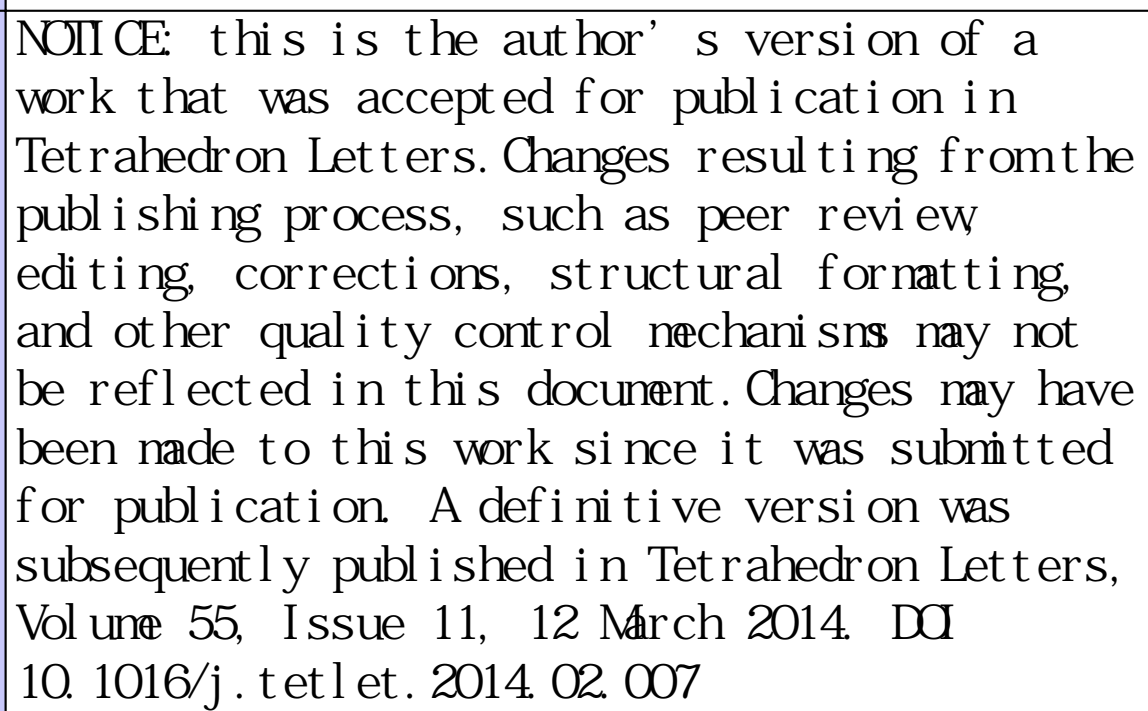 \\
\hline URL & ht t p: //hdl . handl e. net /10297/7775 \\
\hline
\end{tabular}




\title{
Fluorogenic aldehydes bearing arylethynyl groups: turn-on aldol reaction sensors for evaluation of organocatalysis in DMSO
}

\author{
Nobuyuki Mase ${ }^{\mathrm{a}} *$, Taishi Ando ${ }^{\mathrm{a}}$, Fumiya Shibagaki ${ }^{\mathrm{a}}$, Atsushi Sugita ${ }^{\mathrm{a}}$, Tetsuo Narumi ${ }^{\mathrm{a}}$, Mitsuo Toda ${ }^{\mathrm{a}}$, \\ Naoharu Watanabe ${ }^{\mathrm{a}}$ and Fujie Tanaka ${ }^{\mathrm{b}}{ }_{*}$ \\ ${ }^{a}$ Department of Applied Chemistry and Biochemical Engineering, Graduate school of Engineering, and Green Energy Research Division, Research Institute of \\ Green Science and Technology, Shizuoka University, 3-5-1 Johoku, Hamamatsu, Shizuoka 432-8561, Japan \\ ${ }^{b}$ Chemistry and Chemical Engineering Unit, Okinawa Institute of Science and Technology Graduate University, 1919-1 Tancha, Onna, Okinawa 904-0495, \\ Japan
}

\section{ARTICLE INFO}

\section{Article history:}

Received

Received in revised form

Accepted

Available online

\section{Keywords:}

Fluorogenic probe

Fluorescent molecules

High-throughput screening

Carbon-carbon bond formation

Organocatalysis

\section{ABSTRACT}

Fluorogenic aromatic aldehydes bearing arylethynyl groups were developed. They were used for monitoring the reaction progress of organocatalytic aldol reactions in DMSO through an increase in the fluorescence intensity based on the formation of the florescent aldol product. The ratios of the fluorescence intensities of the aldols to the aldehydes were more than 300 . These results suggest that the fluorescence assay system using the aldehyde is useful for the rapid identification of superior aldol catalysts and reaction conditions.

2009 Elsevier Ltd. All rights reserved.
The methods for monitoring the reaction progress of chemical transformations through an increase in the fluorescence intensity are useful for screening of catalysts and reaction conditions, as well as the characterization of catalysis on a small scale. ${ }^{1}$ Various fluorogenic substrates have been developed for monitoring the reaction progress of catalytic cleavage reactions, functional group transformations, ${ }^{2,3,4}$ and bond-forming including carbon-carbon bond-forming reactions. ${ }^{5,6,7,8,9}$ Practical utility of the substrates have been demonstrated..$^{10}$ Herein, we report the synthesis and the use of fluorogenic aldehydes bearing arylethynyl groups that are suitable for monitoring the organocatalytic aldol reactions in DMSO that is frequently used as an organic solvent in such reactions.

As previously reported, aldol reaction progress can be monitored through an increase in fluorescence using a fluorogenic aldehyde. ${ }^{7}$ To be of practical use, the ratio of fluorescence intensity of the aldol product to that of the fluorogenic aldehyde should be high and the aldehyde should show no fluorescence or very weak fluorescence. ${ }^{7}$ In addition, the reactivity of aldehyde group in fluorogenic aldehyde should be appropriate for the use. ${ }^{11}$ We have recently reported use of 9anthraldehyde to monitor peptide-catalyzed aldol reactions in aqueous solutions. ${ }^{7 \mathrm{c}}$ However, the reactivity of 9-anthraldehyde was relatively low in both aqueous and DMSO conditions (vide infra); this may be because the 9-anthracene moiety acts as a bulky group and hinders the reactions. To develop fluorescence monitoring systems with appropriate reactivity that retain desired fluorescence features of 9-anthraldehyde and its aldols, aldehydes smaller than 9-anthraldehyde such as naphthaldehydes and benzaldehyde derivatives conjugated to aryl groups were designed (Scheme 1). These aldehydes and their aldol products were synthesized or purchased and evaluated in fluorescence and organocatalytic reactivity in DMSO.

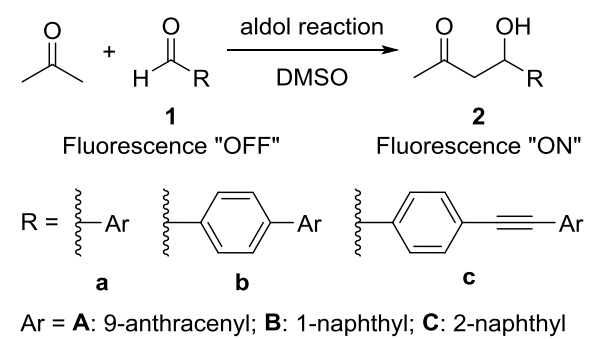

Scheme 1. Fluorogenic substrates for aldol reactions

The syntheses of 4-arylbenzaldehyde derivatives $\mathbf{1 b}$ and 4arylethynylbenzaldehyde derivatives $\mathbf{1 c}$ are shown in Scheme 2.

\footnotetext{
* Corresponding author. Tel.: +81-53-478-1196; fax: +81-53-478-1196; e-mail: tnmase@ipc.shizuoka.ac.jp

* Corresponding author. Tel.: +81-98-966-1552; fax: +81-98-966-1064; e-mail: ftanaka@ oist.jp
} 
The Pd/C-catalyzed phosphine-free Suzuki-Miyaura reactions ${ }^{12}$ of 4-bromobenzaldehyde (3) and boronic acids $\mathbf{4}$ at room temperature afforded the 4-arylbenzaldehyde derivatives $\mathbf{1 b A}$ 1bC in moderate to excellent (21-94\%) yields (Scheme 2). 4Ethynylbenzaldehyde (5) was synthesized from $\mathbf{3}$ and trimethylsilylacetylene (TMSA) in $76 \%$ yield over two steps. ${ }^{13}$ The Sonogashira coupling reactions ${ }^{14}$ of aldehyde $\mathbf{5}$ and aryl bromides $\mathbf{6}$ at $80{ }^{\circ} \mathrm{C}$ afforded the corresponding aldehydes $\mathbf{1 c A}-$ $\mathbf{1 c C}$ in moderate to good (37-58\%) yields.

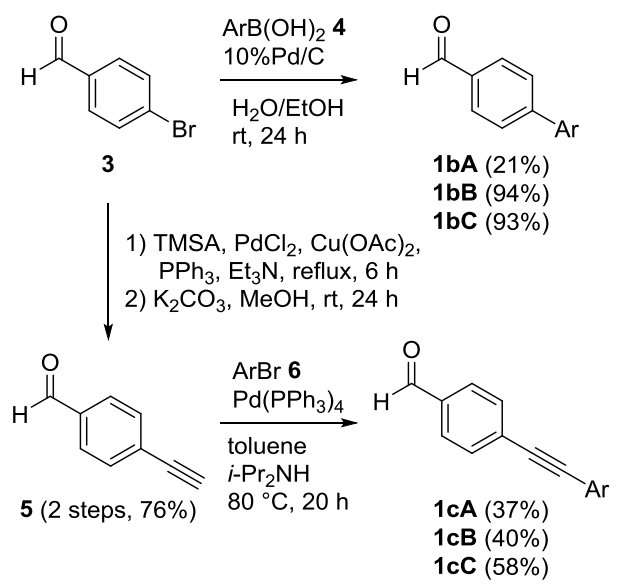

$\operatorname{Ar}=\mathbf{A}:$ 9-anthracenyl; $\mathbf{B}:$ 1-naphthyl; $\mathbf{C}:$ 2-naphthyl

Scheme 2. Preparation of benzaldehyde derivatives 1.

Aldols 2 were prepared by the organocatalytic L-prolinecatalyzed aldol reactions ${ }^{15}$ between acetone and benzaldehyde derivatives 1 (Scheme 3). Nine derivatives $\mathbf{2 a A} \mathbf{A}-\mathbf{2 c C}$ were prepared in moderate to good $(41-81 \%)$ yields at room temperature without any special operation.

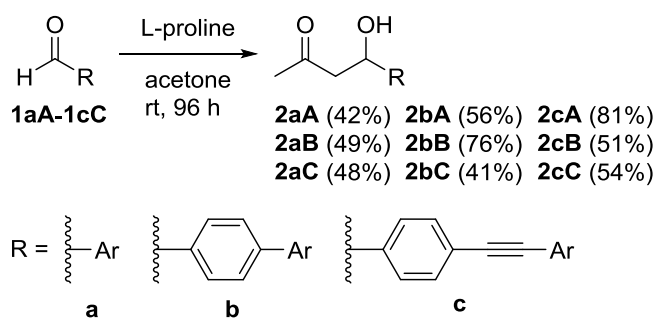

Ar = A: 9-anthracenyl; B: 1-naphthyl; C: 2-naphthyl

Scheme 3. Organocatalytic aldol reactions of benzaldehyde derivatives $\mathbf{1}$.

First, aldehydes 1aA-1aC were evaluated. 9-Anthraldehyde (1aA) emits very weak fluorescence in many solvents upon UV irradiation at the appropriate wavelengths, ${ }^{16}$ whereas, it is known that anthracen-9-ylmethanol emits strong blue fluorescence. ${ }^{17}$ Similarly, aldol $\mathbf{2 a A}$ was highly fluorescent in DMSO. ${ }^{7 \mathrm{c}}$ The ratio of the fluorescence intensities of $\mathbf{2 a A}$ to $1 \mathbf{a A}$ was 322 in DMSO (Table 1, entry 1). To test the utility of $\mathbf{1 a A}$ for monitoring the reaction progress of a typical organocatalytic aldol reaction, the reaction between acetone and aldehyde 1aA was performed using L-proline as the catalyst, and the fluorescence intensity was recorded (Figure 1, see also the Supplementary Material for the details of the fluorescence spectra). Although aldol 2aA was highly fluorescent, the increase in the fluorescence intensity observed during the reaction was low; the slope over $1 \mathrm{~h}$ was 0.09 . The L-proline-catalyzed aldol reaction of aldehyde $\mathbf{1 a A}$ with acetone to afford $\mathbf{2 a A}$ was too slow to obtain any reasonable data. The bulkiness of the 9anthracenyl group probably caused the slow reaction. When less bulky naphthalene derivatives $\mathbf{1 a B} / \mathbf{2 a B}$ and $\mathbf{1 a C} / \mathbf{2 a C}$ were evaluated, no fluorescence was observed at $1 \mu \mathrm{M}$ concentration in DMSO under the UV irradiation at 220 and $235 \mathrm{~nm}$, respectively (Table 1 , entries 2 and 3). Although naphthalene derivatives are known to be fluorescent, ${ }^{18}$ the results of the fluorescence measurements of $\mathbf{1 a B} / \mathbf{2} \mathbf{a B}$ and $1 \mathbf{a C} / \mathbf{2 a C}$ in DMSO indicate that naphthaldehydes are not good fluorogenic substrates for the analysis of the formation of the aldols at the initial stages of the reactions.

Next, arylbenzene derivatives $\mathbf{1 b}$ and arylethynylbenzene derivatives 1c were evaluated. Aldehydes $\mathbf{1 b A}-\mathbf{1 b C}$ and $\mathbf{1 c A}-$ $\mathbf{1 c C}$ emitted very weak fluorescence, whereas aldols $\mathbf{2 b A}-\mathbf{2 b C}$ and $\mathbf{2 c A}-\mathbf{2 c C}$ emitted strong fluorescence in DMSO under the irradiation at appropriate wavelengths (Table 1, entries 4-9). The ratios of the fluorescence intensities of $\mathbf{2 b} / \mathbf{1} \mathbf{b}$ varied from 4.6 to 60 (Table 1, entries 4-6), whereas those of $\mathbf{2 c / 1} \mathbf{c}$ were more than 100 (Table 1, entries 7-9). The best pair of aldol/aldehyde among those tested was $\mathbf{2} \mathbf{c B} / \mathbf{1} \mathbf{c B}$ with a fluorescence intensity ratio of 368 (Table 1, entry 8). ${ }^{19}$ The UV light images of aldehyde $\mathbf{1 c B}$ and aldol $\mathbf{2 c B}$ clearly shows the OFF-ON property of the pair (Figure 2).
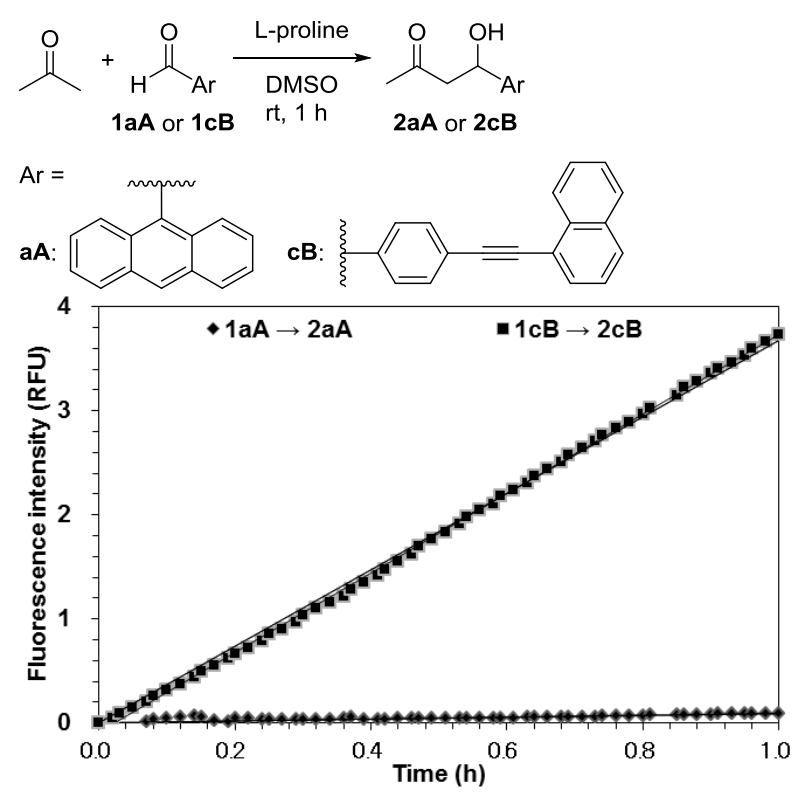

Fig. 1. Fluorescence monitoring of aldol reactions; reaction conditions: aldehyde $(10 \mu \mathrm{M})$, L-proline $(1 \mathrm{mM})$ in $20 \%$ acetone/75\% DMSO/5\% $\mathrm{H}_{2} \mathrm{O}$; reaction volume $3 \mathrm{~mL}$; the reaction was performed in a quartz cuvette. For the reaction of $\mathbf{1 a A}$ with acetone, the fluorescence intensity of $\mathbf{2 a A}$ was monitored at $\lambda_{\mathrm{ex}}=265 \mathrm{~nm}$ and $\lambda_{\mathrm{em}}=420 \mathrm{~nm}$; the slope over $1 \mathrm{~h}$ was 0.09 . For the reaction of $\mathbf{1 c B}$ with acetone, the fluorescence intensity of $\mathbf{2 c B}$ was monitored at $\lambda_{\mathrm{ex}}=330 \mathrm{~nm}$ and $\lambda_{\mathrm{em}}=351 \mathrm{~nm}$; the slope over $1 \mathrm{~h}$ was 3.68 . (a)

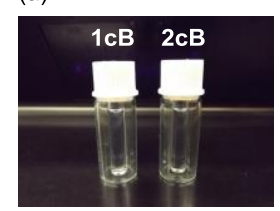

(b)

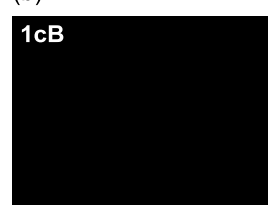

(c)

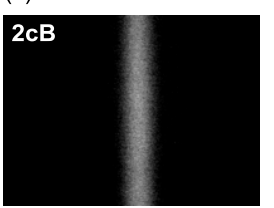

Fig. 2. Photographs of the solutions of 1-naphthylethynylbenzene derivatives in DMSO (0.1 $\mathrm{mM}$ ): (a) aldehyde 1cB and aldol $\mathbf{2 c B}$ under visible light; (b) aldehyde 1cB and (c) aldol 2cB under UV light at $\lambda_{\mathrm{ex}}=254 \mathrm{~nm}$ (UV lamp), $\lambda_{\mathrm{em}}=300-400 \mathrm{~nm}$ (UV camera with filters BLF-390B and UTVAF50S-33U, Sigma Koki Co., Ltd., Japan). 
Table 1. Fluorescent properties of aryl aldehyde derivatives $\mathbf{1}$ and the corresponding aldols 2 .

\begin{tabular}{|c|c|c|c|c|c|c|c|}
\hline \multirow[t]{2}{*}{ Entry } & \multicolumn{2}{|c|}{ Wavelength (nm) } & \multicolumn{4}{|c|}{ Fluorescence intensity } & \multirow[t]{2}{*}{ fold } \\
\hline & $\lambda \mathrm{ex}$ & $\lambda \mathrm{em}$ & Alde & & Aldo & & \\
\hline 1 & 265 & 419 & 1aA & $1.66 \times 10^{1}$ & $2 \mathbf{a A}$ & $5.34 \times 10^{3}$ & 322 \\
\hline 2 & 220 & - & 1aB & - & $\mathbf{2 a B}$ & - & - \\
\hline 3 & 235 & - & $1 \mathrm{aC}$ & - & $\mathbf{2 a C}$ & - & - \\
\hline 4 & 265 & 401 & 1bA & $4.17 \times 10^{1}$ & $2 \mathrm{bA}$ & $2.49 \times 10^{3}$ & 60 \\
\hline 5 & 300 & 342 & $1 \mathrm{bB}$ & $5.66 \times 10^{1}$ & $2 \mathrm{bB}$ & $2.63 \times 10^{2}$ & 4.6 \\
\hline 6 & 270 & 363 & $1 \mathrm{bC}$ & $8.51 \times 10^{1}$ & $2 \mathrm{bC}$ & $1.33 \times 10^{3}$ & 16 \\
\hline 7 & 270 & 432 & $1 \mathrm{cA}$ & $6.16 \times 10^{1}$ & $2 \mathrm{cA}$ & $8.21 \times 10^{3}$ & 133 \\
\hline 8 & 330 & 351 & $1 \mathrm{cB}$ & $2.08 \times 10^{1}$ & $2 \mathrm{cB}$ & $7.65 \times 10^{3}$ & 368 \\
\hline 9 & 330 & 347 & $1 \mathrm{cC}$ & $2.12 \times 10^{1}$ & $2 \mathrm{cC}$ & $6.42 \times 10^{3}$ & 303 \\
\hline
\end{tabular}

All the measurements were carried out in $1.0 \mu \mathrm{M}$ DMSO solution.

Aldehyde 1cB showed the lowest fluorescence among aldehydes $\mathbf{1 b A}-\mathbf{1 b C}$ and $\mathbf{1 c A}-\mathbf{1 c C}$; therefore, the utility of aldehyde $\mathbf{1 c B}$ in monitoring the reaction to afford aldol $\mathbf{2 c B}$ was examined. The time course of the L-proline-catalyzed aldol reaction of acetone with aldehyde $\mathbf{1 c B}$ showed a significant increase in the fluorescence intensity (Figure 1); the slope over 1 $\mathrm{h}$ was 3.68. This slope was 41 -fold greater than that of the Lproline-catalyzed reaction of $\mathbf{1 a A}$ with acetone to afford aldol 2aA. These results indicate that aldehyde $\mathbf{1 c B}$ is an excellent fluorogenic aldehyde for monitoring the reaction progress of aldol reactions in DMSO.

In summary, we developed fluorogenic aldehydes that can be used to monitor the reaction progress of L-proline-catalyzed aldol reactions in DMSO through an increase in the fluorescence intensity. This type of fluorescence assay system may be useful for the rapid identification of superior aldol catalysts. The studies on the full scope of the fluorescence monitoring systems for chemical transformations using fluorogenic substrates containing arylethynylbenzene moieties are currently under investigation and will be reported in due course.

\section{Acknowledgments}

This study was supported in part by a Grant-in-Aid for Young Scientists (A) (No. 23685035) for scientific research from the Japan Society for the Promotion of Science.

\section{Supplementary Material}

Supplementary data of fluorescence spectra and synthesis and characterization of compounds associated with this article can be found, in the online version, at doi:10.1016/XX.

\section{References and notes}

1. Reviews on fluorogenic substrates: (a) Finney, N. S. Curr. Opin. Chem. Biol. 2006, 10, 238-245; (b) Goddard, J.-P.; Reymond, J.-L. Trends Biotechnol. 2004, 22, 363-370; (c) Evans, C. A.; Miller, S. J. Curr. Opin. Chem. Biol. 2002, 6, 333-338.

2. Recent reports on the detection of bond-cleavage reactions in enzyme assay: (a) Baba, R.; Hori, Y.; Mizukami, S.; Kikuchi, K. J. Am. Chem. Soc. 2012, 134, 14310-14313; (b) Kumada, H.-O.; Nguyen, J.-T.; Kakizawa, T.; Hidaka, K.; Kimura, T.; Hayashi, Y.; Kiso, Y. J. Pept. Sci. 2011, 17, 569-575; (c) Sicart, R.; Collin, M.P.; Reymond, J.-L. Biotechnol. J. 2007, 2, 221-231.

3. Recent reports on the detection of bond-cleavage reactions: (a) Shibata, A.; Furukawa, K.; Abe, H.; Tsuneda, S.; Ito, Y. Bioorg. Med. Chem. Lett. 2008, 18, 2246-2249; (b) Yang, X.-F.
Spectrochim. Acta, Part A 2007, 67, 321-326; (c) Wu, J.-S.; Kim, H. J.; Lee, M. H.; Yoon, J. H.; Lee, J. H.; Kim, J. S. Tetrahedron Lett. 2007, 48, 3159-3162.

4. Recent reports on the detection of $\mathrm{C}-\mathrm{C}$ bond-cleavage reactions: (a) Sevestre, A.; Charmantray, F.; Hélaine, V.; Lásiková, A.; Hecquet, L. Tetrahedron 2006, 62, 3969-3976; (b) Kofoed, J.; Darbre, T.; Reymond, J.-L. Org. Biomol. Chem. 2006, 4, 32683281; (c) Jourdain, N.; Carlón, R. P.; Reymond, J.-L. Tetrahedron Lett. 1998, 39, 9415-9418; (d) List, B.; Barbas, C. F., III; Lerner, R. A. Proc. Natl. Acad. Sci. U. S. A. 1998, 95, 15351-15355.

5. Recently reported fluorogenic probes for bond-forming chemical transformations and detecting molecules of interest by covalent bond-forming reactions: (a) Mizukami, S.; Watanabe, S.; Akimoto, Y.; Kikuchi, K. J. Am. Chem. Soc. 2012, 134, 1623-1629; (b) Lang, K.; Davis, L.; Wallace, S.; Mahesh, M.; Cox, D. J.; Blackman, M. L.; Fox, J. M.; Chin, J. W. J. Am. Chem. Soc. 2012 134, 10317-10320; (c) Shieh, P.; Hangauer, M. J.; Bertozzi, C. R. J. Am. Chem. Soc. 2012, 134, 17428-17431; (d) Friscourt, F.; Fahrni, C. J.; Boons, G.-J. J. Am. Chem. Soc. 2012, 134, 1880918815; (e) Zhang, H.; Wang, P.; Yang, Y.; Sun, H. Chem. Commun. 2012, 48, 10672-10674; (f) Komatsu, T.; Johnsson, K.; Okuno, H.; Bito, H.; Inoue, T.; Nagano, T.; Urano, Y. J. Am. Chem. Soc. 2011, 133, 6745-6751; (g) Eor, S.; Hwang, J.; Choi, M. G.; Chang, S.-K. Org. Lett. 2011, 13, 370-373; (h) Jewett, J. C.; Bertozzi, C. R. Org. Lett. 2011, 13, 5937-5939; (i) Zhang, C.J.; Li, L.; Chen, G. Y. J.; Xu, Q.-H.; Yao, S. Q. Org. Lett. 2011, 13, 4160-4163.

6. Tanaka, F.; Thayumanavan, R.; Barbas, C. F., III. J. Am. Chem. Soc. 2003, 125, 8523-8528.

7. (a) Tanaka, F.; Mase, N.; Barbas, C. F., III. J. Am. Chem. Soc 2004, 126, 3692-3693; (b) Guo, H.-M.; Tanaka, F. J. Org. Chem. 2009, 74, 2417-2424; (c) Mase, N.; Takabe, K.; Tanaka, F. Tetrahedron Lett. 2013, 54, 4306-4308; (d) Katsuyama, I.; Chouthaiwale, P. V.; Akama, H.; Cui, H.-L.; Tanaka, F. Tetrahedron Lett. 2014, 55, 74-78.

8. Guo, H.-M.; Minakawa, M.; Tanaka, F. J. Org. Chem. 2008, 73, 3964-3966.

9. Recent reports on the detection of $\mathrm{C}-\mathrm{C}$ bond-forming reactions: (a) Jo, J.; Olasz, A.; Chen, C.-H.; Lee, D. J. Am. Chem. Soc. 2013, 135, 3620-3632; (b) Sonawane, Y. A.; Phadtare, S. B.; Borse, B. N.; Jagtap, A. R.; Shankarling, G. S. Org. Lett. 2010, 12, 14561459; (c) Do, J. H.; Kim, H. N.; Yoon, J.; Kim, J. S.; Kim, H.-J. Org. Lett. 2010, 12, 932-934; (d) Kim, G.-J.; Kim, H.-J. Tetrahedron Lett. 2010, 51, 4670-4672; (e) Jo, J.; Lee, D. J. Am. Chem. Soc. 2009, 131, 16283-16291; (f) Zhao, D.; Wang, W.; Yang, F.; Lan, J.; Yang, L.; Gao, G.; You, J. Angew. Chem. Int. Ed. 2009, 48, 3296-3300; (g) Rozhkov, R. V.; Davisson, V. J.; Bergstrom, D. E. Adv. Synth. Catal. 2008, 350, 71-75; (h) Umeda, N.; Tsurugi, H.; Satoh, T.; Miura, M. Angew. Chem. Int. Ed. 2008, 47, 4019-4022.

10. (a) Mase, N.; Tanaka, F.; Barbas, C. F., III. Org. Lett. 2003, 5, 4369-4372; (b) Mase, N.; Tanaka, F.; Barbas, C. F., III. Angew. Chem. Int. Ed. 2004, 43, 2420-2423; (c) Mase, N.; Thayumanavan, R.; Tanaka, F.; Barbas, C. F., III. Org. Lett. 2004, 6, 2527-2530; (d) Tanaka, F.; Thayumanavan, R.; Mase, N.; Barbas, C. F., III 


\section{Tetrahedron}

Tetrahedron Lett. 2004, 45, 325-328. (e) Tanaka, F.; Mase, N.; Barbas, C. F., III. Chem. Commun. 2004, 1762-1763.

11. Katsuyama, I.; Chouthaiwale, P. V.; Cui, H.-L.; Ito, Y.; Sando, A.; Tokiwa, H.; Tanaka, F. Tetrahedron 2013, 69, 4098-4104.

12. Zhang, G. Synthesis 2005, 537-542.

13. Wautelet, P.; Moigne, J. L.; Videva, V.; Turek, P. J. Org. Chem. 2003, 68, 8025-8036.

14. Yi, C.; Hua, R. Catal. Commun. 2006, 7, 377-379.

15. (a) List, B.; Lerner, R. A.; Barbas, C. F., III. J. Am. Chem. Soc. 2000, 122, 2395-2396; (b) Sakthivel, K.; Notz, W.; Bui, T.; Barbas, C. F., III. J. Am. Chem. Soc. 2001, 123, 5260-5267.

16. (a) Crowell, E. P.; Varsel, C. J. Anal. Chem. 1963, 35, 189-192; (b) Mitchell, D. J.; Schuster, G. B.; Drickamer, H. G. J. Am. Chem. Soc. 1977, 99, 1145-1148.

17. Vijayalakshmi, N.; Maitra, U. Org. Lett. 2005, 7, 2727-2730.

18. (a) Liu, J.-F.; Chi, Y.-G.; Peng, J.-F.; Jiang, G.-B.; Jönsson, J. Å. J. Chem. Eng. Data 2004, 49, 1422-1424; (b) Kang, K.-D.; Jones, P.
D.; Huang, H.; Zhang, R.; Mostovich, L. A.; Wheelock, C. E.; Watanabe, T.; Gulyaeva, L. F.; Hammock, B. D. Anal. Biochem. 2005, 344, 183-192.

19. The ratios of the fluorescence intensities of $\mathbf{2} \mathbf{c B} / \mathbf{1} \mathbf{c B}$ in various solvents: 232 -fold in $\mathrm{CHCl}_{3}$ (at $\lambda_{\mathrm{ex}}=320 \mathrm{~nm}$ and $\lambda_{\mathrm{em}}=347 \mathrm{~nm}$ ), 323 -fold in AcOEt (at $\lambda_{\mathrm{ex}}=318 \mathrm{~nm}$ and $\lambda_{\mathrm{em}}=343 \mathrm{~nm}$ ), 22-fold in 2-PrOH (at $\lambda_{\mathrm{ex}}=318 \mathrm{~nm}$ and $\lambda_{\mathrm{em}}=343 \mathrm{~nm}$ ), 764-fold in $\mathrm{CH}_{3} \mathrm{CN}$ (at $\lambda_{\mathrm{ex}}=318 \mathrm{~nm}$ and $\lambda_{\mathrm{em}}=343 \mathrm{~nm}$ ), 31-fold in DMF (at $\lambda_{\mathrm{ex}}=324$ $\mathrm{nm}$ and $\left.\lambda_{\mathrm{em}}=347 \mathrm{~nm}\right)$, and 15 -fold in Na phosphate buffer ( $\mathrm{pH} 7$, at $\lambda_{\mathrm{ex}}=238 \mathrm{~nm}$ and $\lambda_{\mathrm{em}}=360 \mathrm{~nm}$ ). The fluorescence intensity of aldol 2cB in different solvent analyzed in the above-indicated $\lambda_{\mathrm{ex}}$ and $\lambda_{\mathrm{em}}$ wavelengths relative to that in DMSO (2cB in DMSO at $\lambda_{\mathrm{ex}}=330 \mathrm{~nm}$ and $\lambda_{\mathrm{em}}=351 \mathrm{~nm}: 100$ ) was following: $\mathrm{CHCl}_{3}: 97$; AcOEt: 117; 2-PrOH: 121 ; $\mathrm{CH}_{3} \mathrm{CN}$ : 119; DMF: 108; Na phosphate buffer (pH 7): 14. 